American Journal of Surgical Research and Reviews
(ISSN:2637-5087)

\title{
The validity of Protein S 100B in Mild Pediatric Head Trauma
}

\author{
Magdy A. Lolah ${ }^{1 \#,}$, Khaled A. Khalifa ${ }^{2}$, Tarek M. E. Rageh ${ }^{3}$, Adel Hamed Elbaih ${ }^{4 \#}$, Mohamed A. \\ Hussein $^{5}$, Mai T. B. Meshhal ${ }^{6}$ \\ ${ }^{1}$ Department of General Surgery, Faculty of Medicine, Menoufia University, Egypt \\ ${ }^{2}$ Department of Clinical Pathology, Faculty of Medicine, Menoufia University, Egypt \\ ${ }^{3}$ Department of General Surgery, Faculty of Medicine, Menoufia University, Egypt \\ ${ }^{4}$ Department of Emergency Medicine, Faculty of Medicine, Suez Canal University, Ismailia, Egypt, \\ and Sulaiman Al-Rajhi University, Clinical Medical Science, Saudi Arabia \\ ${ }^{5}$ Department of Neurosurgery, Faculty of Medicine, Menoufia University, Egypt \\ ${ }^{6 *}$ Department of Emergency medicine, Faculty of Medicine, Menoufia University, Egypt \\ ${ }^{*}$ Equal contribution
}

\section{ABSTRACT}

Background; S100B has been shown to be beneficial as a biomarker in the treatment of adults with mild traumatic brain injury

*Correspondence to Author: (mTBI). The efficacy of S100B as a biomarker in children, on the Mai T. B. Meshhal other hand, has been a subject of debate. Aim and objectives; was to assess the validity of Protein S 100B in Mild Pediatric Department of Emergency mediHead trauma. Subjects and methods; this was a prospective study, included 160 pediatric patients with mild head trauma presented to Emergency Department. Result; A highly significant correlation between Positive S100B protein and traumatic brain injury with S100B protein value $1554.1 \pm 84.0 \mathrm{ng} / \mathrm{L}$. A100 had cutoff value for positive CT Brain finding above $987.5 \mathrm{ng} / \mathrm{L}$, The sensitivity was $81.0 \%$, the specificity was $75 \% \%$, the NPV was $86 \%$, the PPV was $68 \%$, and overall accuracy $77 \%$. There was none statistical significant difference regarding severity of brain injury and S100 B ( $P=0.225)$, Conclusion; Serum S100B levels cannot be used to substitute clinical examinations or CT scans in identifying pediatric patients with mild head injuries, but they can be used to identify low-risk kids to avoid excessive radiation exposure.

Keywords: S100B, biomarker, CT Brain, mild head injuries, Pediatric. cine, Faculty of Medicine, Menoufia University, Egypt

How to cite this article:

Magdy A. Lolah, Khaled A. Khalifa, Tarek M. E. Rageh, Abel Hamed El bail, Mohamed A. Hussein, Mai T. B. Meshhal. The validity of Protein S 100B in Mild Pediatric Head Trauma. American Journal of Surgical Research and Reviews, 2021, 4:29.
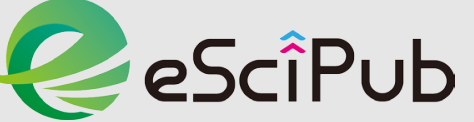

eSciPub LLC, Houston, TX USA. Website: https://escipub.com/ By using the site/services, you are agreeing to our Policies: https:// escipub.com/terms-privacy-policydisclaimer/ 


\section{INTRODUCTION}

It is a well-known fact that trauma is a worldwide problem and a main cause of morbidity and mortality universally. In the first four decades of life, the most common cause of death is trauma [1].

Traumatic brain injury [TBI] is one of the most widely used presentations to the emergency department, which accounts for more than 500 000 visits of children per year in the USA ${ }^{[2]}$. Mild [82.7\%], moderate [12.5\%], and severe head damage were the initial severity of traumatic brain damage as determined by the Glasgow Coma Scale [GCS] [4.7\% ${ }^{[3]}$.

More than $95 \%$ percent of head injuries in children are classified as mild head trauma [MHT], which is defined as a Glasgow Coma Scale [GCS] score of 13 or above on computed tomography. Less than $10 \%$ of these individuals suffer traumatic brain injuries [TBI], and less than $1 \%$ require neurosurgery ${ }^{[4]}$.

Between 1995 and 2005, the number of children who had a head computed tomography scan more than doubled. CT is reported to be used in about half of children with moderate traumatic brain damage in some settings ${ }^{[5]}$.

In the United States, the usage of head computerized tomography [CT] has increased thrice in the last decade without an increase in the rate of life-threatening diagnoses being detected ${ }^{[6]}$.

In children younger than ten years, the risk of developing leukemia or brain tumors from a single CT scan is estimated to be 1 in 10,000 . The same study found that numerous scans with radiation doses ranging from two to three head CTs [approximately $60 \mathrm{mGy}$ total brain exposure] tripled the risk of brain cancers [RR 3.32] when compared to doses of less than 5 mGy ${ }^{[7]}$.

S100B protein has long been recognized as a useful tool for detecting the initiation or progression of brain injury, as well as associating with a poor prognosis in a variety of neuro critical illnesses, including TBI, subarachnoid hemorrhage, stroke, and brain death ${ }^{[8]}$. The S100B protein can help a doctor decide whether a head CT is necessary for a child under the age of 16 who has had a minor head injury. Its high sensitivity suggests it could be a useful tool for determining whether or not an intracranial damage exists. However, because of its low specificity, it can't be utilized as a stand-alone marker; however, when combined with clinical decision guidelines, S100B could help reduce the number of needless CT scans [9]. S100B measurement, according to the American College of Emergency Physicians, might cut the number of unneeded CT scans by $30 \%$ [10].

\section{PATIENTS \& METHODS}

This was a prospective study, included 160 pediatric patients with mild head trauma presented to Emergency Department

Inclusion criteria: Age below 18 years old, Both sexes, Mild head trauma According to the American Congress of Rehabilitation Medicine is a patient with a GCS of 13 or more who has had a traumatically induced physiologic disruption of brain function, as manifested by at least one of the following: Any period of loss of consciousness less than $30 \mathrm{~min}$, Any loss of memory for events immediately before or after the accident [posttraumatic amnesia should last $<24 \mathrm{hr}$ ], Any alteration in mental state at the time of the accident [eg, feeling dazed, disoriented, or confused] and Focal neurologic deficit[s] that may or may not be transient

Exclusion criteria: Pediatric patients with moderate or severe head injury, Patients with underlying medical conditions affecting results of study like bleeding tendency and Patients transferred from other hospitals after performing any medical or surgical procedure.

Methods: Pediatric patients with mild head trauma presented to manage according to Advanced Trauma Life support Guidelines [ATLS] consisting of primary survey, secondary survey and adjuncts. 
- Primary survey assessment by $A B C D E$ approach with its adjuncts

Airway: Airway assessment for patency by speaking to the patient and absence of hoarseness or stridor or gurgling sound for upper airway secretions. Assessment for airway protection by presence of airway reflexes And Exclusion of risk factors for airway compromise as facial burn, neck vascular injury, massive surgical emphysema, GCS 8 or less, Use of oxygen mask. Stabilize spinal column with spinal motion restriction techniques. Take X.ray for Cervical spine

\section{Breathing:}

1. Assessment of breathing by examination: Inspection: inspect chest wall for respiratory rate, any visible chest open wounds, contusions, lacerations, stab wounds, paradoxical respiration indicating flail segment. Palpation: palpation of chest wall for equal chest expansion, any clicks for fracture ribs and surgical emphysema. Percussion: percussion of chest wall for excluding hyperresonance indicating pneumothorax or dullness indicating hemothorax. Auscultation: auscultation of equal bilateral breath sounds, detecting any additional sounds as crepitation, wheezes and auscultation of heart sounds.

Excluding life threatening injuries as tension pneumothorax, cardiac tamponade, flail chest, massive hemothorax and open pneumothorax.

2. Use of pulse oximetry to detect oxygen saturation

3. Take chest X-ray.

Circulation: Assessment of circulation by reading blood pressure, heart rate, capillary refill time and urine output monitoring, abdominal examination by Inspection for any bruises, evisceration and Palpation for pelvic stability, tenderness. Focussed Assessment Sonography for Trauma, Inserting 2 wide bore canula, taking blood sample for ABO typing, cross matching, labs. Take a venous blood sample for S100B protein serum analysis. Take a pelvic X-ray.
Disability: Neurological assessment and disability: Level of consciousness: ageappropriate Glasgow Coma Scale, signs of lateralization and Pupil size bilateral and reactivity, Random blood sugar reading and Order CT brain for our pediatric patients with mild head trauma

CT barin through the skull base to the vertex done and trauma-relevant lesions [subdural, epidural, or intracerebral hemorrhages; bland contusion; edema; pneumocephalus; and skull fracture] were searched for and blinded to the S100-B level.

Exposure: Exposure from head to toe and Log Roll the patient to search for any hidden injuries and examine the back. Keep dignity of the patient by exposing part by part. Avoid hypothermia during exposure

\section{Secondary survey}

$\checkmark$ AMPLE history: Allergies, Medication. Past medical history, Last meal, Event of trauma, Mechanism of injury and ask about symptoms of mild traumatic brain injury: Any period of loss of consciousness less than 30 min. Any loss of memory for events immediately before or after the accident [posttraumatic amnesia should last $<24 \mathrm{hr}$. Any alteration in mental state at the time of the accident [eg, feeling dazed, disoriented, or confused]. Focal neurologic deficit[s] that may or may not be transient

$\checkmark$ Examination: Organized, complete examination to detect additional injury.

\section{$\checkmark$ Investigations}

\section{$>$ CT Brain was done for all our patients.}

\section{> S 100 Protein analysis.}

Statistical analysis: The data collected were tabulated and analyzed by SPSS statistical package version 20 on IBM compatible computer. Quantitative data were expressed as mean and standard deviation $[\mathrm{X} \pm \mathrm{SD}]$, and qualitative data expressed as number and percentage [No. \&\%]. Analysis was by applying Pearson's Chi-Square test and Fisher's exact 
test. Level of significance set as $P$ value $<0.05$. Rule of S100B protein to predict TBI in CT Brain was evaluated

\section{RESULTS}

The socio-demographic data of our study showing that Males of our patients [88] $55 \%$ more than females [72] $45 \%$ of our patients, age of our patients range from 3 months -15 years with mean age 5.0 \pm 3.8 . Table [1]

Different clinical data in our patients with mild head trauma definition showing most common MOT among our patients was FFH $40 \%$ and RTA $40 \%$ with severe mechanism of injury in $37 \%$ of the patients. AMS was the presentation in $25 \%$ of the patients. Cephalhematoma was found in $32.5 \%$ of the patients Temporal $15 \%$, Parietal $12.5 \%$, Occipital $8 \%$. Loss of consciousness was the presentation in $27.5 \%$ $\%$ of the patients with duration more than 5 secs in $91 \%$ of them. Abnormal behaviour to the parents was the complaint in $32.5 \%$ of our patients. Patients presented by vomiting were $62.5 \%$ of the patients with number of vomiting mean \pm SD $1.5 \pm 1.3$ ranging from 1 - 4 times.
Headache presented in $5 \%$ of our patients. On recording CT Brain finding we found traumatic brain injury in $40 \%$ of patients and in $60 \%$ of patients no traumatic brain injury signs found. Table [2]

A highly significant correlation between Positive S100B protein and traumatic brain injury with S100B protein value $1554.1 \pm 84.0 \mathrm{ng} / \mathrm{L}$. Table [3] A100 had cutoff value for positive CT Brain finding above $987.5 \mathrm{ng} / \mathrm{L}$. The sensitivity was $81.0 \%$, the specificity was $75 \% \%$, the NPV was $86 \%$, the PPV was $68 \%$, and overall accuracy $77 \%$. Table [4]

There was none statistical significant difference regarding severity of brain injury and S100 B $[P$ $=0.225]$. Table [5]

The multiple logistic regression models between positive vs. negative CT pathology in patient with minor head trauma showed that Low GCS, vomiting, abnormal behavior to the parents, nonfrontal hematoma and abnormal mental status were independent significant predictive factors to increased risk of pathology in CT by $4.4,10.4$, $1.2,7.5$ and 24.2 times respectively. Table [6]

\section{Table 1: Socio-demographic data of the studied cases [no=160]}

\begin{tabular}{|c|c|}
\hline \multicolumn{2}{|l|}{ Variables } \\
\hline $\begin{array}{cl}\text { Age [years] } \\
\qquad \quad \text { Mean } \pm S D \\
-\quad \text { Range }\end{array}$ & $\begin{array}{l}5.0 \pm 3.8 \\
3 \text { months - } 15 \text { years }\end{array}$ \\
\hline $\begin{array}{l}\text { Gender } \\
\qquad \quad \text { Male } \\
\text { - } \text { Female }\end{array}$ & $\begin{array}{ll}88 & {[55.0 \%]} \\
72 & {[45.0 \%]}\end{array}$ \\
\hline
\end{tabular}

Table 2: Clinical data analysis in the studied cases:

\begin{tabular}{|l|lc|}
\hline Clinical data analysis & \multicolumn{2}{|l|}{} \\
\hline Mode of trauma [MOT] & 4 & {$[2.5 \%]$} \\
- Falling from stairs & 64 & {$[40.0 \%]$} \\
- Falling from height [FFH] & 28 & {$[17.5 \%]$} \\
- localized head trauma & 64 & {$[40.0 \%]$} \\
- Road traffic accident [RTA] & 100 & {$[62.5 \%]$} \\
\hline sever mode of trauma & 60 & {$[37.5 \%]$} \\
- No & $14.6 \pm 0.73 \quad[13.0-15.0]$ \\
\hline - Yes & \multicolumn{2}{|l|}{} \\
\hline Altered mental status [AMS] & \multicolumn{2}{|l|}{} \\
\hline
\end{tabular}


Magdy A. Lolah et al., AJSRR, 2021 4:29

\begin{tabular}{|c|c|}
\hline $\begin{array}{ll}\text { - } & \text { No } \\
\text { - } & \text { Yes }\end{array}$ & $\begin{array}{ll}120 & {[75.0 \%]} \\
40 & {[25.0 \%]}\end{array}$ \\
\hline $\begin{array}{l}\text { Cephalhematoma } \\
\text { - Occipital } \\
\text { - Partial } \\
\text { - Temporal }\end{array}$ & $\begin{array}{l}{[5.0 \%]} \\
{[12.5 \%]} \\
{[15.0 \%]}\end{array}$ \\
\hline $\begin{array}{l}\text { Loss of consciousness } \\
\begin{array}{l}\text { - No } \\
-\quad \text { Yes }\end{array}\end{array}$ & $\begin{array}{ll}116 & {[72.5 \%]} \\
44 & {[27.5 \%]}\end{array}$ \\
\hline $\begin{array}{l}\text { Loss of consciousness duration } \\
\text { - Less than } 5 \mathrm{sec} \\
\text { - More than } 5 \mathrm{sec}\end{array}$ & $\begin{array}{l}{[9.0 \%]} \\
{[91.0 \%]}\end{array}$ \\
\hline $\begin{array}{l}\text { Abnormal behavior to parents } \\
\text { - Yes } \\
-\quad \text { No }\end{array}$ & $\begin{array}{ll}52 & {[32.5 \%]} \\
108 & {[67.5 \%]}\end{array}$ \\
\hline $\begin{aligned} \text { Vomiting } \\
\text { - No } \\
-\quad \text { Yes }\end{aligned}$ & $\begin{array}{ll}60 & {[37.5 \%]} \\
100 & {[62.5 \%]}\end{array}$ \\
\hline $\begin{array}{l}\text { Number of vomiting } \\
\text { - } \quad \text { Mean } \pm S D \\
\text { - } \quad \text { Range }\end{array}$ & $\begin{array}{l}1.5 \pm 1.3 \\
1.0-4.0\end{array}$ \\
\hline $\begin{array}{l}\text { Headache } \\
\text { - No } \\
\text { - Yes }\end{array}$ & $\begin{array}{ll}152 & {[95.0 \%]} \\
8 & {[5.0 \%]}\end{array}$ \\
\hline $\begin{array}{l}\text { CT finding } \\
-\quad \text { Positive } \\
\text { - } \text { Negative }\end{array}$ & $\begin{array}{ll}64 & {[40.0 \%]} \\
96 & {[60.0 \%]}\end{array}$ \\
\hline
\end{tabular}

Table 3: S100 protein level and CT finding

\begin{tabular}{|c|c|c|c|c|}
\hline \multirow{2}{*}{ Variable } & \multicolumn{2}{|l|}{ CT finding } & \multirow{2}{*}{$\mathrm{T}$ test } & \multirow{2}{*}{$P$ value } \\
\hline & Positive & Negative & & \\
\hline $\begin{aligned} \mathrm{S} 100 & \\
\bullet & \text { mean } \pm \mathrm{SD}\end{aligned}$ & $1554.1 \pm 84.0$ & $794.3 \pm 329.8$ & 9.4 & 0.001 \\
\hline
\end{tabular}

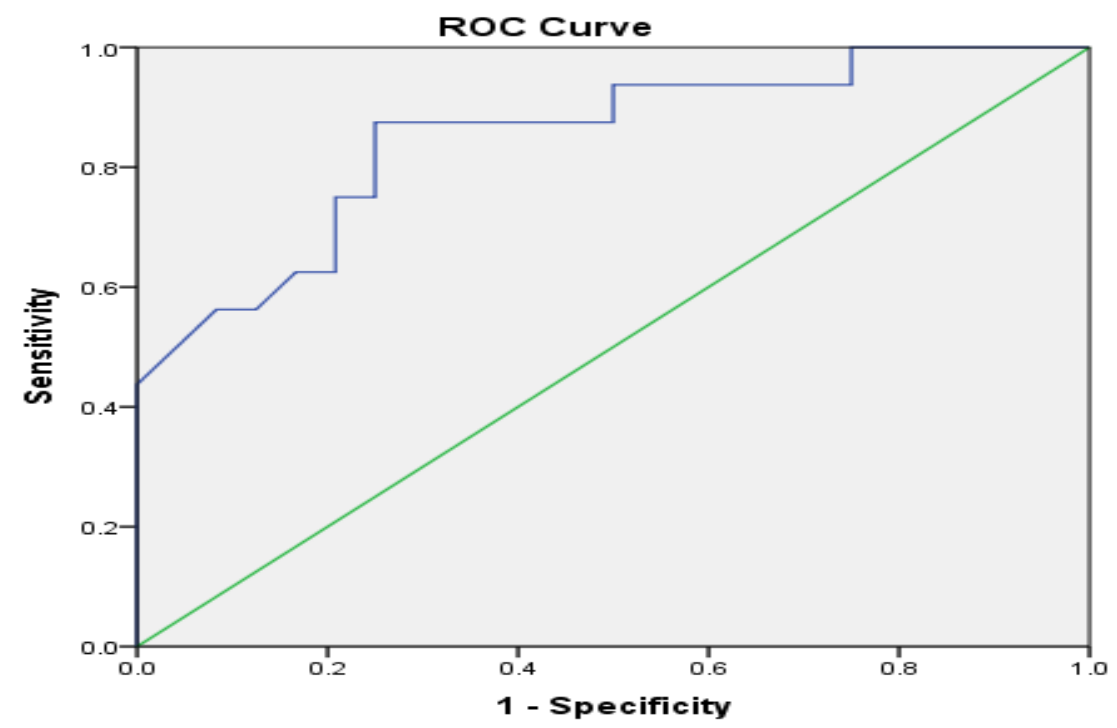

Diagonal segments are produced by ties.

Figure [1]: ROC curve for validity of $\mathbf{S 1 0 0}$ for predication of Traumatic Brain Injury.

AJSRR: https://escipub.com/american-journal-of-surgical-research-and-reviews/ 
Magdy A. Lolah et al., AJSRR, 2021 4:29

\begin{tabular}{l|l|l|l|l|l|l|l}
\hline Variable & $\begin{array}{l}\text { best cut off } \\
\text { point }\end{array}$ & AUC & $\begin{array}{l}\text { Sensitivity } \\
\%\end{array}$ & $\begin{array}{l}\text { Specificity } \\
\%\end{array}$ & PPV\% & NPV\% & Accuracy \% \\
\hline $\mathbf{S 1 0 0}$ & $>987.5$ & 0.850 & $81 \%$ & $75 \%$ & $68 \%$ & $86 \%$ & $77 \%$ \\
\hline
\end{tabular}

AUC [area under the curve] PPV [positive predicative value] NPV [negative predicative value]

Table 5: Correlation between severity of brain injury by CT and S100B

\begin{tabular}{|c|c|c|c|c|}
\hline \multirow[t]{2}{*}{ Variable } & \multicolumn{2}{|c|}{ Severity of brain injury by CT finding } & \multirow[t]{2}{*}{ T test } & \multirow[t]{2}{*}{$P$ value } \\
\hline & Severe & non-severe & & \\
\hline $\begin{array}{r}\mathrm{S} 100 \\
-\quad \text { mean } \pm S D\end{array}$ & $1743.2 \pm 786.8$ & $1310.7 \pm 297.4$ & 1.2 & 0.225 \\
\hline
\end{tabular}

Table 6: Multivariate regression analysis of parameters that may be associated with pathology in CT

\begin{tabular}{|l|l|l|l|}
\hline Variables & P value & Odds ratio & $95 \% \mathrm{Cl}$ \\
\hline Age & 0.805 & 1.0 & $0.89-1.1$ \\
\hline Low GCS & 0.04 & 4.4 & $1.06-18.3$ \\
\hline Vomiting & 0.001 & 10.4 & $3.4-31.8$ \\
\hline Headache & 0.677 & 1.4 & $0.290-7.4$ \\
\hline Abnormal behavior to the parents & 0.717 & 1.2 & $0.342-4.7$ \\
\hline Non-frontal hematoma & 0.001 & 7.5 & $2.8-20.0$ \\
\hline Abnormal mental status & 0.016 & 24.2 & $1.8-321.6$ \\
\hline
\end{tabular}

95\% Confidence interval $[95 \% \mathrm{Cl}]$

\section{DISCUSSION}

Trauma occurs when an uncontrollable force or an acute source of energy comes into direct touch with the body and the body can no longer handle it. Trauma was the eighth largest cause of mortality in Egypt in 2010, accounting for 8\% of the population. Because to underreporting and misclassification, injury is several times higher in Egypt. Many research have attempted to make definitive predictions of brain death following damage; brain death prediction is useful since it allows us to save bodily organs if transplantation is considered [11].

In pediatric populations, traumatic brain injury [TBI] is a common reason for visits to the emergency department. Children's TBI is also one of the top causes of death and morbidity. In pediatric patients, communication challenges can block the correct and timely gathering of a thorough injury history as well as the detection of TBI indicators ${ }^{[12]}$.

In order to reduce death and long-term disability, it is critical to conduct an accurate initial assessment and intervene early in the treatment of patients with HI. Assessing a patient's degree of consciousness, on the other hand, is a tough task, owing to the difficulties in identifying fully objective and user-independent terminology. To meet this demand, several scales have evolved through the years ${ }^{[13]}$.

The aim of the current study was to assess the validity of Protein S 100B in Mild Pediatric Head trauma. 
This was a prospective interventional study that included mild isolated head trauma patients presented to emergency department, where 160 patients were evaluated clinically by PECARN decision rule and taking blood sample for S100B protein then CT Brain for diagnosis of traumatic brain injury.

As regard the socio-demographic data of our study showing that Males of our patients [88] 55 $\%$ more than females [72] $45 \%$ of our patients, and the age of our patients ranged from 3 months -15 years with mean age $5.0 \pm 3.8$ years.

Kelmendi et al., ${ }^{[14]}$ conducted a study on a total of 80 individuals with mild TBI who met the inclusion criteria for this investigation, which agrees with our findings. Forty-six patients were male [57.5\%], and 34 patients were female [42.5\%]. The mean age was 9.1 years [SD \pm 3.8 years].

Between January 2009 and December 2011, Manzano et al., [15] conducted A multicenter prospective cohort study in the pediatric emergency departments of three Swiss tertiary hospitals. A total of 80 patients with mild TBI met the study's inclusion criteria.. Forty-six patients were male 35 [66.0], the mean age was 94.0 [56.5] months.

In the current study, different clinical data in our patients with mild head trauma definition showing most common mode of trauma among our patients was $\mathrm{FFH} 40 \%$ and RTA $40 \%$ with severe mechanism of injury in $37 \%$ of the patients, mean $\pm S D$ of GCS was $14.6 \pm 0.73$ with range [13.0 - 15.0], $25.0 \%$ had altered mental status, as regard CT finding 64 [40.0\%] were Positive and 96 [60.0\%] were negative. AMS was the presentation in $25 \%$ of the patients. Cephalhematoma was found in $32.5 \%$ of the patients Temporal 15\%, Parietal 12.5\%, Occipital $8 \%$. Loss of consciousness was the presentation in $27.5 \% \%$ of the patients with duration more than 5 secs in $91 \%$ of them. Abnormal behaviour to the parents was the complaint in $32.5 \%$ of our patients, Patients presented by vomiting was $62.5 \%$ of the patients with number of vomiting mean \pm SD 1.5 \pm 1.3 ranging from $1-4$ times and Headache presented in $5 \%$ of our patients. On recording CT Brain finding we found traumatic brain injury in $40 \%$ of patients and in $60 \%$ of patients no traumatic brain injury signs found.

Elbaih et al., ${ }^{[11]}$ reported that regarding the mechanism of trauma; the direct trauma was the most common cause of head trauma [47.7\%], followed by motor car accident [MCA] [31.8\%].

These results were not similar to the results by Egea-Guerrero et al., ${ }^{[16]}$ in which MCA was the most common cause of head trauma [60\%] in the patients. This may be due to the inclusion criteria of patients in both studies as they selected severe head trauma in polytrauma patients, while in our study the selected patients had only isolated severe head trauma not associated with extracranial injuries, Elbaih et al., [11] showed that the mean GCS among patients with severe head trauma was $6.59 \pm 1.49$ which was associated with tachypnea and tachycardia. This was similar to the results of a study performed by Shakeri et al., ${ }^{[17]}$ in which the average of primary GCS score of patients was $5 \pm 2$.

According to Kelmendi et al., ${ }^{[12]}$, the participants were divided into two groups: [a] a negative CT group [CT-], which included patients with no evidence of cranial damage on CT; and [b] a positive CT group [CT+], which included patients with at least one trauma-related lesion on CT.., most common mode of trauma among their patients was $\mathrm{FFH} 21 \%$ and RTA $23 \%$ with severe mechanism of injury in $31.3 \%$ of the patients, 44 [55.0] had loss of consciousness.

$\mathrm{S} 100 \mathrm{~B}$ is associated with cell differentiation and cell cycle progression, and under experimental conditions, it has been demonstrated to suppress apoptosis. Extracellulary, given S100B increases neurogenesis and neuronal plasticity, executes neuro-modulating effects, and improves memory and learning processes in both normal and stressful settings. ${ }^{[18] .}$ 
In the present study, we demonstrated that there was highly significant correlation between Positive S100B protein and traumatic brain injury with S100B protein value $1554.1 \pm 84.0$ $\mathrm{ng} / \mathrm{L}$.

In the prospective study of Kelmendi et al., [12], the mean $5100 B$ level in our series was $0.398 \mu \mathrm{g} \mathrm{L}^{-1}\left[\mathrm{SD} \pm 0.298 \mu \mathrm{g} \mathrm{L}^{-1}\right.$ ], and the $95 \% \mathrm{Cl}$ ranged from 0.332 to $0.465 \mu \mathrm{g} \mathrm{L}^{-1}$. A total of 53 patients $[66.3 \%]$ had cranial lesions, Patients with cranial injury, as demonstrated by $\mathrm{CT}$, had higher S100B protein levels than those without cranial injury $[p<0.0001]$. The mean serum S100B protein level in patients without cranial injury [head CT-] was $0.145 \mu \mathrm{g} \mathrm{L}^{-1}[95 \% \mathrm{Cl}$ $\left.0.138-0.152 \mathrm{~g} \mathrm{~L} \mathrm{~L}^{-1}\right]$, while the mean serum S100B protein level in patients with cranial injury [head $\left.\mathrm{CT}_{+}\right]$was $0.527 \mu \mathrm{g} \mathrm{L}^{-1}[95 \% \mathrm{Cl} 0.447-$ $0.607 \mu \mathrm{g} \mathrm{L}^{-1}$ ].

On the other hand, we found that $\mathrm{s} 100$ had cutoff value for positive CT Brain finding above 987.5 $\mathrm{ng} / \mathrm{L}$. The sensitivity was $81.0 \%$, the specificity was $75 \% \%$, the NPV was $86 \%$, the PPV was $68 \%$, and overall accuracy $77 \%$.

In Elbaih et al., [11], study, the ROC analysis showed that the $2 \mathrm{~h} \mathrm{S100B}$ could predict the conservative way of management with AUC [0.76, $P=0.002]$ with a sensitivity of $76 \%$ and specificity of $75 \%$ with fair accuracy $[76 \%]$, while the ROC analysis of the $48 \mathrm{~h} \mathrm{S100B}$ showed better AUC [0.94, $\mathrm{P}=0.00$ ] with a sensitivity of $100 \%$ and specificity of $86 \%$ with excellent accuracy [90\%]. Also in the same study, the ROC analysis showed that the $2 \mathrm{~h} \mathrm{S100B}$ had the ability to predict the length of stay in the ICU with AUC [0.8, $P=0.000]$ with a sensitivity of $58 \%$ and specificity of $100 \%$ with good accuracy [80\%].

Similar to the results by Egea-Guerrero et al., [16] in which the ROC curve showed that S100B had AUC 0.80 at admission and 0.86 at $24 \mathrm{~h}$ later and in their study in order to maximize the relationship between sensitivity and specificity, they used the highest AUC plot [24 h] to assign a cutoff value for serum S100B [0.372 $\mu \mathrm{g} / \mathrm{l}]$ with $85.7 \%$ sensitivity, $79.3 \%$ specificity, $18.7 \%$ positive predictive value, and $98.9 \%$ negative predictive value. These dissimilarities may be due to the difference in the time of sample collection and the variance in the cutoff value as they collected the samples at admission and after $24 \mathrm{~h}$, while in our study, the samples had been collected at $2 \mathrm{~h}$ after admission and $48 \mathrm{~h}$ after head trauma.

When children were included within 3 hours after the TBI, Bouvier et al., ${ }^{[19]}$ discovered a $100 \%$ sensitivity and a $33 \%$ specificity. Others 27 32 , on the other hand, exhibited the same sensitivity as well as greater specificity when included children within 6 hours. Furthermore, in the present study, there was none statistical significant difference regarding severity of brain injury and S100 B [P = 0.225], this in comparison with the study of Abdelfattah et al., [20] which reported that he median level of protein $\mathrm{S} 100 \mathrm{~B}$ in survivors was $0.33,0.26$, and $0.14 \mu \mathrm{g} / \mathrm{L}$, respectively but in non-survivors, the median level was $0.4,1.7$, and $2.9 \mu \mathrm{g} / \mathrm{L}$, respectively.

Another interesting finding is that we assessed the multiple logistic regression models between positive vs. negative CT pathology in patient with minor head trauma showed that Low GCS, vomiting, abnormal behavior to the parents, nonfrontal hematoma and abnormal mental status were independent significant predictive factors to increased risk of pathology in CT by $4.4,10.4$, 1.2,7.5 and 24.2 times respectively.

Our results were in agreement with Andrade et al., ${ }^{[21]}$ of the 1006 children assessed, 101 had some abnormalities on head computed tomography scans, with 49 being hospitalized, 16 being kept under surveillance, and 36 being discharged. There was no neurosurgery performed on any of the patients. There was no statistically significant link seen between patient age, period between incident and admission, or trauma-related signs/symptoms and aberrant imaging results. There was a statistically significant link $[p=0.044]$ between aberrant imaging results and a fall greater than 1.0 metre.

The limitations of our study are although we used an average sample size, the sample size
8 
was still small and the study could not be blind which might have introduced some bias into the results. Additionally, the accuracy of S100B dimer as a diagnostic and prognostic tool is still debatable and could not be precisely detected from other causes that lead to chronic S100B dimer rise, which may lead to its rise in the initial evaluation, so it should be scanned and rolled out from the start.

\section{CONCLUSION}

To summarize, serum S100B levels cannot be used to substitute clinical examinations or CT scans in identifying pediatric kids with moderate head injuries; nevertheless, they can be used to identify low-risk individuals and avoid excessive radiation exposure.

Incorporating recommendations for S100B level measurement into the guidelines for the management of mild head injury could eliminate the need for an unnecessary CT scan, which is currently recommended for patients with mild head injuries, reducing radiation exposure in the pediatric population while also saving valuable healthcare resources. Measuring S100B protein levels in emergency patients may help to enhance emergency care by minimizing needless testing and lengths of stay in crowded emergency departments.

Consent for Publication: I confirm that all authors accept the manuscript for submission.

\section{REFERENCES}

[1]. Mohameda MA, Mahmoud S. El-Desokya , Mohamed A. E. Elhamzawy, Evaluation of Prince of Wales Hospital score in predicting massive blood transfusion in trauma, Menoufia Med $\mathrm{J}$ 32:1246-125, DOI: $10.4103 / \mathrm{mmj} . \mathrm{mmj} \_302 \_18$.

[2]. Rutland-Brown W. "Incidence of traumatic brain injury in the United States, 2003." The Journal of head trauma rehabilitation. 2006; 21[6]: 544-548.

[3]. Hassan, Neven A. "Pattern of craniofacial injuries in patients admitted to Tanta University HospitalEgypt." Journal of forensic and legal medicine. 2010; 17[1]: 26-32.

[4]. Pandor A. "Diagnostic management strategies for adults and children with minor head injury: a systematic review and an economic evaluation." Health technology assessment [Winchester, England]. 2011; 15[27]: 1.

AJSRR: https://escipub.com/american-journal-of-surgical-research-and-reviews/
[5]. Kuppermann N. "Identification of children at very low risk of clinically-important brain injuries after head trauma: a prospective cohort study." The Lancet. 2009; 374 [9696]: 1160-1170.

[6]. Melnick ER, Szlezak CM, Bentley SK, Dziura JD, Kotlyar S, Post LA. CT overuse for mild traumatic brain injury. Jt Comm J Qual Patient Saf. 2012; 38:483-9

[7]. Pearce, Mark S. "Radiation exposure from CT scans in childhood and subsequent risk of leukaemia and brain tumours: a retrospective cohort study." The Lancet. 2012; 380 [9840]: 499-505.

[8]. Rodríguez-Rodríguez, Ana. "Role of S100B protein in urine and serum as an early predictor of mortality after severe traumatic brain injury in adults." Clinica chimica acta. 2012; 414: 228233.

[9]. Manzano, Sergio. "Diagnostic performance of S100B protein serum measurement in detecting intracranial injury in children with mild head trauma." Emerg Med J. 2016; 33[1]: 42-46.

[10]. Jagoda, Andy S. "Clinical policy: neuroimaging and decisionmaking in adult mild traumatic brain injury in the acute setting." Journal of Emergency Nursing. 2009; 35[2]: e5-e40.

[11]. Elbaih AH, Mohammed MA, Ali MA, Elshemaly AA, Mostafa MS. Validity of S100B protein as a prognostic tool in isolated severe head injuries in emergency patients. Egypt J Surg. 2020; 39: 795-806. Available from: http://www.ejs.eg.ne t/text.asp?2020/39/3/795/293680.

[12]. Kristman V. L., Borg J., Godbolt A. K. Methodological issues and research recommendations for prognosis after mild traumatic brain injury: Results of the international collaboration on mild traumatic brain injury prognosis. Archives of Physical Medicine and Rehabilitation. 2014; 95[3]:S265-S277. doi: 10.1016/j.apmr.2013.04.026.

[13]. Fakhry T, Salah R, Gaber A. Full outline of unresponsiveness versus Glasgow coma scale in predicting mortality in paediatric trauma patients. Int Surg J 2019;6:2279-85

[14]. Kelmendi F. M., Morina A. A., Mekaj A. Y., Blyta A., Alimehmeti R., Dragusha S., et al. Serum S100B Levels Can Predict Computed Tomography Findings in Paediatric Patients with Mild Head Injury. BioMed research international, 2018; 6954045. https://doi.org/10.1155/2018 16954045 . 
[15]. Manzano S, Holzinger IB, Kellenberger CJ. Diagnostic performance of S100B protein serum measurement in detecting intracranial injury in children with mild head trauma, Emerg Med $\mathrm{J}$. 2016; 33: 42-46.

[16]. Egea-Guerrero JJ, Murillo-Cabezas F, GordilloEscobar E, Rodríguez-Rodríguez A, EnamoradoEnamorado J, Revuelto-Rey J et al. S100B protein may detect brain death development after severe traumatic brain injury. J Neurotrauma. 2013; 30:1762-1769.

[17]. Shakeri M, Mahdkhah A, Panahi F. S100B protein as a post-traumatic biomarker for prediction of brain death in association with patient outcomes. Arch Trauma Res. 2013; 2:7680.

[18]. Kleindienst A, Grunbeck F, Buslei R, Emtmann I, Buchfelder $M$. Intraperitoneal treatment with S100B enhances hippocampal neurogenesis in juvenile mice and after experimental brain injury. Acta Neurochir [Wien]. 2013; 155:1351-1360.

[19]. Bouvier D, Fournier M, Dauphin JB. Serum $\mathrm{S} 100 \mathrm{~B}$ determination in the management of pediatric mild traumatic brain injury. Clin Chem 2012;58:1116-22.

[20]. Abdelfattah E, Marwa N, Mohamed A, Khaled F, Abdelraouf. Prognostic Value of Protein S100B in Traumatic Brain Injury, The Egyptian Journal of Critical Care Medicine, 2020; 7[2]: 80-85 doi: 10.1097/EJ9.0000000000000016

[21]. Andrade FP., Montoro N, Roberto O, Renan L, Gabriela F, Luana G, et al. Pediatric minor head trauma: do cranial CT scans change the therapeutic approach?. Clinics. 2016; 71[10]: 606-610. https://doi.org/10.6061/clinic s/2016[ $10] 09$. 